\title{
The Influence of Entrepreneurship Education on Employment Quality and Its Optimization Strategy in Colleges and Universities
}

\author{
Tianwen Liu, Yunsong Huang, Mingche Cong, Shuang Li \\ Applied Technology College \\ Dalian Ocean University \\ Dalian Liaoning, 116000, China
}

\begin{abstract}
Entrepreneurship education, as a relatively new approach to improving students' entrepreneurial quality, has been becoming an organic part of quality education for college students. Nowadays, how to give full play to the role of entrepreneurship education, thus better cultivating the entrepreneurial quality of college students, is becoming one of the urgent problems we need to address. Based on the research of entrepreneurship education in colleges and universities and the employment situation faced by college graduates nowadays, this work put forward some problems existing in entrepreneurial education. It first analyzed influencing factors of entrepreneurship education on employment quality, and then proposed some effective countermeasures to promote employment of college graduates, offering entrepreneurial employment education theoretical basis.
\end{abstract}

Keywords-entrepreneurship education; employment quality; optimization countermeasure

\section{INTRODUCTION}

The employment difficulty of college graduates has become a key and difficult problem of current economic and social development. Leaders of China have clearly put forward the development strategy of mass entrepreneurship. What is more, colleges and universities attach great importance to the issue of entrepreneurship and employment of college students, and set off a wave of innovation and entrepreneurship of college students in the new era. Therefore, colleges and universities should strengthen the support for entrepreneurship and employment of college students, highlight the quality training of college students, and improve the quality of graduate employment.

\section{ANALYSIS OF EMPLOYMENT SitUATION FOR COLLEGE GRADUATES}

\section{A. The relatively large scale of employment population}

At the end of the last century, colleges and universities have gradually expanded their scale, so that the number of college students has gradually expanded and the number of students has increased year by year. The current difficulty in employment of college graduates is mainly related to the large number of graduates. In 1998, colleges and universities implemented enrollment expansion, and the number of graduates entering the market every year was large. However, the number of social jobs currently does not match the number of college graduates, resulting in a big contradiction between the employment population and employment posts. The imbalance of supply and demand in the talent market is one of the most realistic problems faced by college graduates.

\section{B. Low salary treatment of college graduates}

Nowadays, the employment of college graduates is a twoway choice. In this process, college graduates flood into the market, making the supply and demand in the job market unbalanced. The supply exceeds demand, which makes employment more difficult. In addition, the requirements of enterprises in graduates are gradually improved, and college students' initial employment salary is relatively low, which affects their confidence and living conditions. According to the data, the current monthly salary of undergraduate graduates in the market is less than 1,500 yuan. There are still many enterprises giving wages that are below average level to college students during the trial period, causing a vicious circle that some college students refuse to work and stay at home.

\section{Unemployment among college graduates is relatively common}

According to the survey, at the beginning of the $21 \mathrm{st}$ century, the voluntary unemployment rate of college graduates in China reached more than $20 \%$, which directly reflected the employment situation of college graduates in China. The combination of previous graduates and new graduates has made the employment of newly graduated college students more difficult and the employment situation more serious. At present, unemployment of college graduates is a relatively common phenomenon. Students lacking work experience and interpersonal experience are inevitable to make some mistakes when they start to work. It is common that some students are unemployed because of their work and working environment. 
and universities is not stable, and the faculty strength is weak. It is difficult to meet the requirements of entrepreneurship education since the number and experience of teachers are lacking. At present, many teachers of entrepreneurship education in colleges and universities are the mentor of entrepreneurship training, and many of them are concurrently responsible for employment guidance. These teachers lack entrepreneurship or investment experience, and have insufficient understanding of the essence of entrepreneurship. Only relying on indirect understanding and learning theory is less practical and will affect the entrepreneurial theories promotion of college graduates. students have fewer opportunities for extracurricular interaction, and the quality of entrepreneurship education is low. Some colleges and universities generally pay more attention to the employment rate of college graduates, but neglect the importance of entrepreneurship education, and they excessively use entrepreneurship as an excuse for employment. The concept of entrepreneurship education in colleges and universities is relatively backward, resulting that students lack entrepreneurial awareness and have narrow awareness of entrepreneurship education. Furthermore, college graduates pay more attention to the work that is not easy to be laid off. For example, many students choose to become civil servants after graduation, and choose to enter state-owned enterprises and large private enterprises. There are more people in these positions than those who choose to start a business. Some students only pay attention to the form when they participate in the entrepreneurial competition. In order to win the competition bonuses, some students are limited by multiple factors, so that their business plan is difficult to be put into practice.

\section{B. The entrepreneurship education curriculum in colleges and universities is not perfect}

Nowadays, many colleges and universities start entrepreneurship courses one after another, but most of them choose to set them as elective courses, and they only hold entrepreneurial competitions on a regular basis. Consequently, the establishment of entrepreneurship curriculum system is not perfect, the curriculum time is not scientific, and the practice curriculum system is not perfect. At present, the content of entrepreneurship courses offered by colleges and universities is relatively simple, generally using large-scale enterprises as the main case. Since college graduates usually establish smallscale companies when they choose to start a business, this kind of curriculum is difficult to meet the practical requirements of college students. In actual course education, small-scale enterprises are rarely used as cases, and teachers play a dominant role in teaching. As a result, the personality development of graduates is limited.

\section{The faculty strength of entrepreneurship education is weak}

Entrepreneurship education of college graduates is closely related to the strength of teachers. Teachers are the people who propagate the doctrine, impart professional knowledge, and resolve doubts, so they are important mentors in guiding college students. Therefore, it is necessary to attach importance to the adjustment of the faculty strength of college entrepreneurship education and strengthen the construction of faculty team. However, the actual situation is that the number of teachers engaged in entrepreneurship education in college

\section{Fewer opportunities for entrepreneurship education}

The entrepreneurial education of college students should not only pay attention to the implementation of theoretical courses, but also pay attention to the development of entrepreneurial practice. Colleges and universities should provide entrepreneurial service platforms for college students. However, the actual situation is that although some colleges and universities in China have set up entrepreneurial parks and training bases, the practice forms of entrepreneurship are relatively simple. Many colleges and universities only formalize the whole process, and teachers play an inadequate role in guiding students' entrepreneurial practice. Consequently, students are not active in participating the entrepreneurial practice, and the results of the student entrepreneurship competition are not used for entrepreneurial practice.

\section{THE IMPACT OF ENTREPRENEURSHIP EDUCATION IN COLlEGES AND UNIVERSITIES ON COLLEGE STUDENTS' EMPLOYMENT}

\section{A. Entrepreneurship education is conducive to promoting the transformation of graduates' employment concept}

Entrepreneurship education in colleges and universities is an education model that helps employment. Entrepreneurship is a kind of consciousness and also a concept of employment. Taking scientific entrepreneurship education helps to change the employment concept, understand the current employment situation, and know various industries. At present, college students have a biased employment concept, for example, they are afraid of competition, and their attitude towards employment is not positive and active. Through entrepreneurship education and employment guidance, college students can transform their employment concepts to make them more realistic. By holding various types of activities to create entrepreneurial culture, colleges and universities can improve students' enthusiasm for employment and improve their practical skills and vocational skills, so as to realize selfemployment or career choices, reversing the current employment situation.

\section{B. Entrepreneurship education helps enrich the professional knowledge of graduates}

First, entrepreneurship education is not a one-step process, but a relatively systematic project. The entrepreneurial education curriculum currently set up in colleges and universities helps to enrich the employment knowledge of 


\section{B. Establishing a safeguard mechanism to improve the quality of graduate employment}

Colleges and universities should combine college students' entrepreneurship and employment guidance work to provide guarantee for college students' employment. First of all, it is necessary to ensure that the organization meets the needs. Colleges and universities should establish a perfect college student entrepreneurship guidance service organization, and the government should also introduce corresponding policies to implement scientific entrepreneurship education. All departments should unite and cooperate, focus on the employment training and practice of college students, and provide a scientific basis for college students' employment. Secondly, it is necessary to ensure the requirements of entrepreneurship and employment education personnel, create a double-qualified faculty team, and hire senior management personnel to enrich the team of college teachers, providing strong support for college graduates to start a business. Thirdly, it is important to ensure that the venue meets the requirements. Colleges and universities can establish a business incubation base and establish a practice platform, so as to encourage college students to start a business and achieve the transformation of scientific and technological achievements.

compre ability, and social adaptability, which are all skills that adapt to social enterprise positions. In the practice of entrepreneurship, college graduates are inevitable to communication with teachers, classmates and corporate personnel. College students should understand the actual needs of social enterprise positions and make their own capabilities to meet the actual requirements of enterprises. In addition, students need to plan ahead for entrepreneurial competitions. It is necessary to make time planning and establish a start-up team, which is the key to improving the ability of employment.

\section{EFFECTIVE STRATEGIES FOR COLLEGES AND} UNIVERSITIES TO USE ENTREPRENEURSHIP EDUCATION TO PROMOTE EMPLOYMENT

\section{A. Establishing an entrepreneurship education fund to provide financial support for graduates}

College graduates rarely participate in social practice and lack practical experience in entrepreneurship and employment. In many cases, entrepreneurs face great risks. Students lack sufficient funds to start their own businesses, so government and relevant departments should actively take measures to provide sufficient funds for college students to start their own businesses, so as to promote employment, improve the quality of employment, and ensure the smooth employment of graduates. The financial department and the education department should increase funding, create entrepreneurial funds for college students, and provide loans for college students free of charge. Government departments should pave the way for the projects declared by college students, review the economic and social benefits of student projects, analyze the project market prospects, and actively introduce bank support to provide guarantees for college students' entrepreneurship and employment.

\section{Promoting the reform of entrepreneurship education and improving graduates' ability of employment}

Entrepreneurship education and employment guidance in colleges and universities cannot be fixed. It is necessary to strengthen the reform and adjustment of entrepreneurship education. The entrepreneurship education and employment guidance in colleges and universities should conform to the job needs of social enterprises, and take some measures to improve the quality of entrepreneurship and employment. Colleges and universities in China should fully learn from the experience of entrepreneurship education in some western countries, so as to improve the employment guidance effect of graduates and explore the path of employment suitable for the national conditions of China. Colleges and universities should adjust from the curriculum of entrepreneurship education, strengthen the setting of practical teaching courses, compile practical teaching materials, improve the entrepreneurial education system, increase the content of career planning, strengthen the employment psychological counseling of college students, improve the comprehensive quality of college students, and promote their successful employment after their graduation.

\section{Improving the faculty strength of entrepreneurship education in colleges and universities}

In order to improve the employment quality of college graduates, it is necessary to improve the faculty strength. The quality of entrepreneurial education teachers determines the quality of entrepreneurship education. Colleges and universities should take measures to build a team of teachers with high quality and professional skills. The main measures include selecting teachers regularly to participate in training and correspondence and improving teachers' entrepreneurial education experience and employment guidance. In addition, college teachers should improve their entrepreneurship education skills and employment guidance concepts, update the 
(2) The 13th Five-year Plan Project of Educational Science in Liaoning Province, 2017 (JG17EB030). By Tianwen Liu.

\section{REFERENCES}

[1] Zhang Yiqing. Research on College Students' Innovation and Entrepreneurship Education in the New Period[D]. Xi'an University of Architecture and Technology, 2017.

[2] Yuan Weikun, Wang Mansi. Work-oriented: A New Model of Innovation and Entrepreneurship Education in Colleges and Universities[J]. Higher Education Exploration, 2016(07): 125-128.

[3] Aihua, Zhou Yanji, Zhao Jianlei, et al. Research on the Effect of Innovation and Entrepreneurship Education on College Students' Employment Competitiveness[J]. Higher Education Development Research, 2016(3): 26-29.

[4] Zhang Xilin. Research on the Cultivation of Innovation and Entrepreneurship Ability of Higher Vocational Students Under the Reform of Supply Side[J]. Journal of Liaoning Vocational College, 2017 19(11): 96-98.

[5] Quan Mingwang. Exploring the Practical Path of the Integration of Innovation and Entrepreneurship Education and Employment Guidance in Higher Vocational Colleges[J]. File. 2016 (02)

[6] Chen Ronggui, Yu Zhenghong. Research on Employment and Entrepreneurship in Colleges and Universities Under the Background of Big Data[J]. Journal of Jilin Radio and Television University, 2019 (04): 70-73.

[7] Zhang Kangsi. Factors Influencing the Employment Quality of College Graduates[J]. Population and Economy, 2017 (01): 82-83.

(1) 2018 Key project of Dalian Vocational and Technical Education Research Institute: A Study on the Paths to Conduct Community Education for Vocational Education Colleges (No. DZKY2018A03). By Tianwen Liu.
[8] Liu Tian. The Impact of College Students' Innovation and Entrepreneurship Education on Improving Students' Ability of Employment[J]. Prose Hundred, 2017(8): 169. 